\title{
Analysis on the Significance of Applying Stratified and Classified Teaching in PE
}

\author{
Yanyan Li \\ Xi'an International University, Xi'an, 710077, China
}

Keywords: PE, Stratified and Classified Teaching, Significance, Application

\begin{abstract}
With the constant deepening quality-oriented education, it becomes the major objective for the school teaching to promote students' development in an all-around way. PE can offer positive help in cultivating good ideological qualities of students. Therefore, how to better give the play of PE in teaching, it has already become one major content for teachers to think about. Stratified and classified teaching plays an important role in improving the personal qualities of students. From the meaning of stratified and classified teaching in PE teaching and concrete application, this paper will make brief analysis.
\end{abstract}

\section{Introduction}

Stratified and classified teaching of PE is mainly divided into two contents: namely stratified teaching and classified teaching. The stratified teaching refers to that, based on learning ability and individual difference of teachers need to design the teaching objective into different layers during the teaching process. By adopting proper means and methods, teachers can help students to achieve the teaching objective. Classified teaching refers to that, based on the age, gender and hobbies of educatees, teachers design the teaching contents, further to stimulate learning potentials of students by teaching, promote the comprehensive development of students.

\section{Significance of PE Stratified and Classified Teaching}

\section{Conductive to Implement the Contents of New Curriculum Reform}

The New Curriculum Reform clearly requires teachers to fully respect the individual differences of students during the teaching process, so as to guarantee the development of every student. However, in the current PE teaching, many PE teachers still follow the traditional teaching modes, carry out the one-size-fits-all teaching method and neglect the development of individual differences. Thus there are quite limited students that can really benefit from teaching ${ }^{[1]}$. Therefore, in order to better promote the comprehensive development of students' ability and truly implement the contents of New Curriculum Reform into teaching. Thus it is really necessary to implement the stratified and classified PE teaching.

\section{Conductive to Improve the Level of Teachers}

To implement the stratified and classified teaching, it can provide more scientific and reasonable learning scheme for students at different levels, which has quite important influence on promoting the learning efficiency of students and the teaching level of teachers. For instance, as those students who are not good at PE in the class, those who has specialty, those who are good at theoretical learning and those who have quite good practical ability, teachers can implement the stratified and classified teaching, take care of students at different levels and realize the teaching mode of teaching students in accordance of their aptitude.

\section{Conductive to Realize the Relative Fairness of Education}

It is unrealistic to realize absolutely fair education. Due to influences of regional development and school's construction, it is so difficult to realize the absolutely fair education. Therefore, during the 
teaching process, teachers need to guarantee that all students can receive fair education while guaranteeing the general orientation. It is quite effective to realize the fairness within a small scope by implementing the stratified and classified teaching ${ }^{[2]}$. It needs the school to pay attention to combine the school culture with the local characteristics, further to give the play of stratified and classified teaching. China implements the three-layered management mode, which mainly considers regional differences. As a consequence, it requires the school to try to explore and take advantage of the surrounding resources to teach as much as possible, so as to guarantee the teaching quality of teachers. For instance, for schools in different regions, some school may have quite perfect PE facilities, but some may have quite poor facilities. In case of unexpected factors, such as heavy rain, PE teachers may select to teach in the room or in the gym according to the actual situations of school, further to guarantee the students' right to enjoy the PE teaching.

\section{Conductive to Fully Respect the Individual Differences of Students}

According to investigations and researches, physical conditions of Chinese students have been always performing a declining trend. With the development of times, all kinds of disadvantages have been gradually highlighted. Related departments of our country have attached much importance to those disadvantages. However, from declining indicators of individual students, it does not perform a continuous state. Moreover, the declining indicators during different periods will change as well ${ }^{[3]}$. Moreover, physical conditions of students in some regions do not decline, but increase. It can be seen that, physical conditions of students vary greatly from each other. Consequently, during the process of education, teachers need to adopt different teaching methods and means targeted at students with different physical conditions, so as to improve the physical qualities of students. The stratified and classified PE teaching method is greatly helpful to respect individual differences of students and promote the overall improvement of students' physical qualities.

\section{Conductive to Lifelong Learning of Students}

Students' ability of lifelong learning is mainly laid at school. During the learning period, students can form many good habits and qualities, further to lay a foundation for their life and development in future. However, nowadays, few PE teachers can combine that with lifelong learning during the teaching process, which makes the PE teaching lack certain interest and cannot guide students to form good habits. As a consequence, according to students' gender, ability and hobby, teachers need to set different learning contents for students during teaching process, so as to stimulate their learning interest and help them to master the technique of PE learning. During such a period, teachers can properly guide students, help them to get rid of bad learning habits and guide them to master correct learning methods and techniques, so as to promote their development in the future. All these are implemented on the basis of establishing the stratified and classified teaching.

\section{Obstacles Confronted by Teachers while Implementing the Stratified and Classified PE Teaching}

To implement the stratified and classified PE teaching, there are several major problems as follows: firstly, there are too many students in one class. If the stratified and classified teaching faces a big class, the teacher needs to consider more factors while stratifying students. Besides, there will be more groups. In this way, it will take too much time to teach or demonstrate some knowledge. Thus there will be quite limited time left for students to practice, which will increase difficulty to guidance of teachers. Secondly, qualities of some teachers are still needed to be improved. In some rural areas or resolute areas, PE teachers are usually those who teach other disciplines. Such teachers are insufficient of professional knowledge and techniques. While implementing the stratified and classified teaching, there will be a lot of problems, such as non-standard movements and wrong teaching contents, which will result in the situation that the stratified and classified teaching cannot play its positive role. Effects are not so obvious. Thirdly, proper sites are scarce. Sites are the foundation and precondition that PE teachers give lessons. While carrying out the stratified and 
classified teaching, PE teachers can divide students into several groups, who will practice teaching contents by scattering over the ground. However, due to limited sites, it is hard for some schools to develop the stratified and classified teaching. Fourthly, class teaching time is limited. In the aspect of grouping and organizing order, the PE stratified and classified teaching will cost much time. Usually, one class lasts for 40-45 minutes. There is limited learning time left to students and teachers. PE teachers need to make consistent exploration during the teaching practice, further to find a more proper stratified and classified teaching method.

\section{Major Measures of Realizing PE Stratified and Classified Teaching}

\section{Correctly Understanding Stratified and Classified Teaching}

Before officially implementing the stratified and classified teaching, teachers need to clearly understand the objective and content of stratified and classified teaching. And then,according to the relevant contents of Standard for Compulsory Education PE and Health Curriculum, teachers formulate different objectives for different learning periods. From the aspects of students' physical development situation, learning ability and acquisition of knowledge and techniques, teachers classify students in class, so as to point out the orientation and objective of PE learning for students, and also lay a foundation for officially implementing the stratified and classified teaching ${ }^{[4]}$. Before officially carrying out that, they still need to investigate the overall situation of students in class, further to master students' learning conditions and fundamental abilities. Then, according to actual situations of students in the class, teachers can develop teaching objectives at different levels. For instance, while teaching students to play volleyball, teachers can position the teaching objective as three stages, respectively are mastering, improving and experiencing. Through guidance of effective teaching method, it can enable students to realize the teaching objective and master the PE techniques.

\section{Targeted Guidance}

Targeted guidance refers to that, during the teaching process, teachers need to effectively guide the difficulties and learning methods for students. Therefore, teachers can strengthen their guidance for students from the following two aspects: first of all, teachers need to pay more attention to students during the teaching process, so as guide them in the first time, guide them to correctly master the learning methods and techniques, and also master related PE knowledge. Secondly, teachers should positively communicate with students and help them to solve difficult problems. During the teaching process, teachers need to encourage students to positively solve problems. As those problems they cannot solve, they should ask for teachers' advice positively. Teachers also need to strengthen their communications with students, discover deficiencies of the stratified and classified teaching program in time, so as to adjust and improve the teaching program based on development characteristics of students, enable that to be more scientific and perfect.

\section{Establishing Perfect Evaluation System}

To better implement the stratified and classified PE teaching, it not only needs joint efforts of teachers and students, but also perfect evaluation system, which judges the stratified and classified teaching method. That's because, without a proper evaluation system, it means that students of the same grade use the same evaluation system after learning the PE knowledge. The advantages of stratified and classified teaching method cannot be shown at all, which even hinders the implement of the stratified and classified teaching method to a certain extent ${ }^{[5]}$. Therefore, to really realize the stratified and classified PE teaching, schools need to combine with the actual situations of themselves and establish perfect stratified and classified evaluation system. Thus, schools can establish the evaluation system of stratified and classified teaching from the following aspects. First of all, according to characteristics of students, different evaluation standards should be developed, further to avoid the situation of frustrating enthusiasm of leaning. For instance, while evaluating the situation of 
learning to play basketball, teachers can stratify the boys and girls. It is qualified if a boy has 25 shots, and a girl only needs 15 shots. Moreover, while testing students, teachers need to explain the reason for them. It is caused by differences of boys' and girls' physical and mental development, which is not differential treatment, further to guarantee the learning enthusiasm of students, who will recognize the fairness of the evaluation system. Secondly, it should implement the evaluation by combing the teacher's and student's evaluations together. As the evaluation on PE learning situations of students, it cannot be done from a single aspect. Teachers need to make a comprehensive evaluation on students. To complete the objective formulated by the school, it is only one component of student's academic performance. Teachers still need to make evaluations on students by their performance in class and coordination with them at ordinary times, further to form the learning performance of students, which is helpful for students to form excellent qualities in other aspects.

\section{Paying Attention to the Dominant Position of Students}

New Curriculum Reform specifies that, teachers need to positively play their leading roles during the teaching process, realize the dominant position of students in class, further to stimulate their leaning enthusiasm and promote the improvement of learning effects. The stratified and classified teaching method can effectively give the play of students' dominant position, as follows: firstly, teachers pay attention to characteristics of students and teach the PE contents based on interests of students. According to hobbies of students and requirements of teaching curriculum, the stratified and classified teaching method can set different teaching contents. Before officially selecting classes, teachers should make a brief introduction for them, so as to let them have a rough understanding about the learning content and let them select learning contents by themselves. In this way, it will effectively stimulate their interests in PE contents, encourage them to carefully learn relevant knowledge about PE and guarantee students to positively coordinate with teaching scheme of teachers, further to improve the learning quality of students and teaching level of teachers;

Secondly, teachers should teach students in accordance of their aptitude. The stratified and classified teaching method can take learning ability and physical qualities of students into consideration, further to help students to select contents most suitable to themselves, and then realize the individualized teaching. For instance, if one student has quite poor physical condition, who is often sick but with endurance. Then the teacher can set a teaching objective for him and ask him to insist on running in every morning. In the first one week, the student may be only required to take a lap. And then, according to the running situations of the student, the teacher may gradually increase the lap. In the meanwhile of helping student to improve his physical quality, it can also guarantee the play of advantages.

Thirdly, free practice. During the process of implementing the stratified and classified teaching, the free practice is quite necessary. In the link of free practice, students can be divided into groups and practice their favorite sports, further to actually give the play of dominant role of students. However, during such a process, PE teachers need to control the order of class, reduce the occurrence of accidents and guarantee the smooth development of sports.

\section{Conclusion}

To sum up, with the increasingly deepening and reforming of educational system, PE teachers need to change the traditional teaching methods during the teaching process. Through the stratified and classified teaching method, on the premise of stimulating the learning interest of students, teachers should exercise students' abilities of all aspects, so as to improve the physical qualities of students, cultivate good ideological qualities and lay a good foundation for their life and development in future. 


\section{References}

[1] Wu Xiaoqi. Brief Analysis on the Necessity and Implementing Strategies of Stratified and Classified PE Teaching. Modern Educational Practice and Teaching Research (Electronic Journal), 2015(6):222-223.

[2] Zhao Cong. Explorations of Applying the Stratified and Classified Teaching Method in Colleges and Universities. Sports Time, 2014(21):93-93.

[3] Zhou Yuhua. Application of Stratified and Classified Teaching Method in the Gym Class of Colleges and Universities. Journal of Chifeng University(Natural Science Edition), 2015(7):203-205.

[4] Zhang Xiang. Application of Stratified and Classified Teaching Method in PE Teaching of Primary and Secondary schools. Sports Teaching, 2014(11):43-43.

[5] Zhang Hailing. Experimental Study on the Stratified and Classified Teaching Method in Middle Schools under the Background of New Curriculum Reform. Journal of Simao Normal College, 2010, 26(6): 45-48. 